\title{
ACOUSTIC EMISSION-BASED ANALYSIS OF DAMAGE MECHANISMS IN STEEL FIBRE REINFORCED CONCRETE UNDER MONOTONIC AND CYCLIC LOADING
}

\section{MAURE DE SMEDT*, KRISTOF DE WILDER*, LUCIE VANDEWALLE* AND ELS VERSTRYNGE*}

${ }^{*}$ Department of Civil Engineering, KU Leuven Kasteelpark Arenberg 40 box 2448, 3000 Leuven, Belgium e-mail: maure.desmedt@kuleuven.be

Key words: acoustic emission, damage detection, steel fibre reinforced concrete, cyclic loading

\begin{abstract}
This paper presents the experimental study of monotonic and cyclic behaviour of steel fibre reinforced concrete (SFRC), based on Acoustic Emission (AE) monitoring. Two research scales, namely fibre pull-out tests and bending tests on SFRC, are subjected to monotonic and cyclic loading, combined with AE measurements. In general, the use of non-destructive testing methods leads to a better understanding of the material's behaviour, compared to traditional test setups. The different stages during pull-out and bending, and the corresponding energy dissipation mechanisms, are detected by AE activity and the occurring damage can be localised. Furthermore, upscaling of AE monitoring detects the propagation of damage and its failure modes. It is shown that AE activity, displacement rate and failure mode are linked to fatigue behaviour of SFRC.
\end{abstract}

\section{INTRODUCTION}

Since structural elements are frequently subjected to repeated loading, for example trafficinduced loads or wind action, the fatigue behaviour is of interest for building materials. Adding steel fibres to brittle concrete is known to enhance the post-cracking behaviour and the durability [1 [1 2]. Micro-cracking can be retarded or inhibited by the steel fibres, which leads to a decreased fatigue deterioration. However, the use of SFRC is still restricted with respect to its potential due to the limited amount of cyclic behaviour investigation. Multiple types of testing are used to study the characteristics of SFRC, varying from individual fibres to real-scale partial structures. However, traditional test setups measuring load and displacement rapidly become restricted to study the matrix-fibre interface behaviour, damage propagation and energy dissipation mechanisms during load cycles.
Advanced non-destructive testing (NDT) methods provide important additional knowledge and in-depth insight in the material's behaviour, as shown in literature. X-Ray microfocus Computed Tomography (micro-CT) scanning [3-5] visualises the inner structure of a non-transparent element. For example, the energy dissipation mechanisms of matrix cracking and fibre pull-out can be distinguished and estimated based on micro-CT scanning [6]. Acoustic Emission (AE) monitoring [7, 9] detects early stages of micro-cracking within an element and locates the damage initiation. For example, the fracture process in SFRC can be characterized by means of AE parameters [10], different damage zones in concrete beams can be classified based on the localisation of $\mathrm{AE}$ events [11], and energy dissipation mechanisms during fracture can be distinguished by a trained neural network [12]. 
This research aims to investigate damage mechanisms due to cyclic loading of SFRC by means of AE monitoring. Both fibre pullout tests and bending tests are performed with monotonic and cyclic loading. The first part of the paper elaborates the experimental programme, test specimens and setups are discussed, including the use of acoustic emission monitoring and micro-CT scanning. The second part presents the results and discusses the AE-based investigations according to monotonic behaviour of (1) fibre pull-out and (2) SFRC elements, and (3) cyclic behaviour of SFRC.

\section{EXPERIMENTAL PROGRAMME}

\subsection{Overview}

Two types of SFRC testing are performed, namely individual fibre pull-out tests and threepoint bending tests (3PBT) on SFRC prisms. The former is indicated as 'tests on the first scale', the latter as 'tests on the second scale'.

\subsection{Materials and test specimens}

The concrete mixture is identical for all types of specimens and belongs to concrete class C40/50. The composition contains $350 \mathrm{~kg} / \mathrm{m}^{3}$ CEM I 52.5R HES, $835 \mathrm{~kg} / \mathrm{m}^{3}$ sand $0 / 4$, $1099 \mathrm{~kg} / \mathrm{m}^{3}$ gravel $4 / 14,175 \mathrm{~kg} / \mathrm{m}^{3}$ water and $1 \mathrm{~kg} / \mathrm{m}^{3}(0.3 \%)$ superplasticizer Glenium 51. The mean cube compressive strength $f_{c m}$,cube equals $59 \mathrm{MPa}$, measured according to the European Standard EN12390-3 [13].

During the research, two types of steel fibres have been used, namely Dramix 3D-80/60-BG and Dramix 5D-65/60-BG. Both fibres have a length of $60 \mathrm{~mm}$ and a modulus of elasticity of $200 \mathrm{GPa}$. The 3D hooked-end fibre has a diameter of $0.75 \mathrm{~mm}$ and a tensile strength of $1125 \mathrm{MPa}$, while the 5D fibre has a diameter of $0.92 \mathrm{~mm}$ and a tensile strength of $2300 \mathrm{MPa}$.

Tests on the first scale are performed on concrete cylinders with a height of $50 \mathrm{~mm}$ and a diameter of $30 \mathrm{~mm}$. A 3D or 5D fibre is partially and individually embedded in the cylinder's centre. The fibre's inclination with respect to the vertical loading axis varies between 0 or $30^{\circ}$ and the embedded length equals 10,20 or $30 \mathrm{~mm}$. In total, eight different groups of three to six specimens are tested.

Tests on the second scale are performed on SFRC prisms with dimensions of $150 \times 150 \times$ $660 \mathrm{~mm}^{3}$. 3D or 5D fibres are added with a dosage of $20(0.25 \mathrm{~V} \%)$ or $40 \mathrm{~kg} / \mathrm{m}^{3}(0.5 \mathrm{~V} \%)$, leading to four different groups of six specimens. According to Model Code 2010 [14], the four groups of SFRC mixtures (3D20, 3D40, 5D20, and 5D40) are classified as 1b, 1.5b, $1 \mathrm{c}$, and $1.5 \mathrm{e}$ respectively. In accordance with EN14561 [15], each prism has a notch of $5 \mathrm{x}$ $25 \mathrm{~mm}$, in order to initiate the crack location during the 3PBT.

\subsection{Test setup and loading patterns}

Tests on the first scale are performed with a universal testing machine (Shimadzu AGXMST-X/X-Type, $100 \mathrm{kN}$ maximum capacity). As depicted in Figure 1, the specimen is glued on a steel rod which is clamped in the bottom grip system. The steel fibre's protruding end is securely clamped in the top grip system. The pull-out load and displacement are measured by the testing machine.

Three different loading patterns are applied for the uniaxial pull-out tests, namely (1) monotonic pull-out at $0.6 \mathrm{~mm} / \mathrm{min}$; (2) cyclic loading before the maximum pull-out force has been reached; and (3) cyclic loading after reaching the maximum pull-out force. The frequency, loading limits and number of cycles are variables amongst the tests. All tests are performed until complete fibre pull-out, fibre rupture or specimen failure.

Tests on the second scale are performed with a hydraulic press (Dartec, $5 \mathrm{MN}$ maximum capacity). The distance between supporting rollers equals $500 \mathrm{~mm}$. The load and displacement are measured by the testing machine, and the crack mouth opening displacement (CMOD) by an LVDT. Additionally, five LVDTs are installed over the prism's height, as shown in Figure 2, in order to measure the position of the neutral axis during testing. 


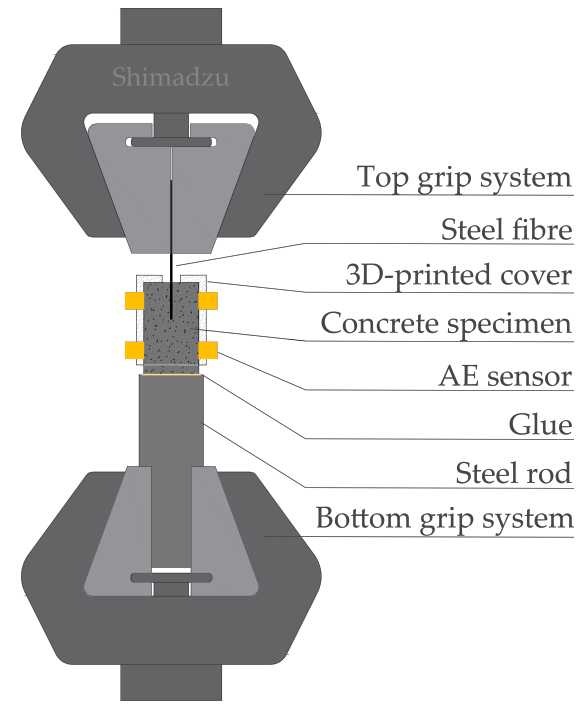

Figure 1: Schematic overview of the pull-out setup (first scale).

For each group of prisms, three specimens are tested monotonically, according to the 3PBT procedure of EN14561 [15]. Three other prisms are subjected to a variable cyclic loading pattern, where the frequency, loading limits and number of cycles are parameters amongst the tests.

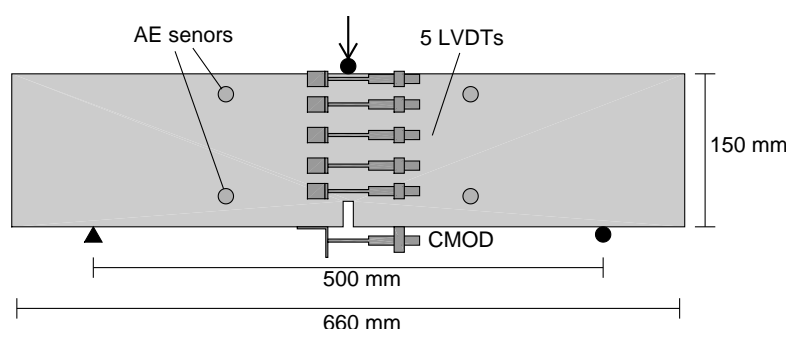

Figure 2: Schematic overview of the 3PBT setup (second scale).

\subsection{Acoustic emission setup}

Tests on both scales are combined with $\mathrm{AE}$ monitoring. In general, four piezoelectric sensors are attached to the specimen's surface by means of vacuum gel. Each sensor is connected to a 4-channel Vallen AMSY-5 acquisition system, using a preamplifier with $34 \mathrm{~dB}$ gain.

During the first scale tests, broadband sensors with a frequency range $50-2000 \mathrm{kHz}$ (Digital Wave B1025) are used. A 3D-printed cover fixes the sensor's position on the specimen, as such that the four sensors form a vertical plane (30 mm width and $27 \mathrm{~mm}$ height) through the specimen's centre. In the acquisition system, a frequency filter of $230-850 \mathrm{kHz}$ and an amplitude threshold of $36.2 \mathrm{~dB}$ are set to avoid background noise. The sampling rate equals $5 \mathrm{MHz}$. From pencil lead breaks, the localisation uncertainty is expected as $5 \mathrm{~mm}$. This is mainly attributed to the large heterogeneity of the concrete specimens.

During the second scale tests, $150 \mathrm{kHz}$ resonance sensors (Vallen VS150-M, frequency range $100-450 \mathrm{kHz}$ ) are used at one side. They form a vertical plane $(240 \mathrm{~mm}$ width and $100 \mathrm{~mm}$ height) around the middle of the prism (refer to Figure 2). In the acquisition system, a frequency filter of $50-850 \mathrm{kHz}$ and an amplitude threshold of $38.2 \mathrm{~dB}$ are set to avoid background noise. The sampling rate equals $10 \mathrm{MHz}$ and a localisation uncertainty of $20 \mathrm{~mm}$ is expected. During post-processing, an additional amplitude filter of $50 \mathrm{~dB}$ has been applied.

\subsection{Micro-CT scanning}

The first scale tests are performed on small sized concrete specimens in order to combine with micro-CT scanning. A Phoenix Nanotom scanning machine is used to visualise the specimen's microstructure at three moments during a test, namely before testing, after applying cyclic loading and after complete fibre pull-out. The current and voltage of the X-ray tube are equal to $200 \mu \mathrm{A}$ and $130 \mathrm{kV}$. The obtained resolution equals $14.9 \mu \mathrm{m}$. Streak artefacts are avoided by a $0.1 \mathrm{Cu}$ filter and a diamond-tungsten target is used to deal with the high density material.

The scans are saved as $2 \mathrm{D}$ projection images and transferred into a 3D array of density values with the Phoenix datos $\mid x 2$ rec software. Afterwards, software CTan, CTvox and DataViewer (Bruker Corporation) are used to analyse the reconstruction of the specimen by 2D slices or $3 \mathrm{D}$ views. The higher density materials, such as steel, are distinguished from the lower density materials, such as air, by their differences in grey scale. Steel has a higher grey-scale and therefore a brighter colour on the images. 


\section{RESULTS AND DISCUSSION}

\subsection{Monotonic behaviour of fibre pull-out}

In total, 40 pull-out tests were performed with varying fibre type, embedded length and inclination. The individual pull-out results will not be discussed, as the focus is put on the AE measurements. In general, the influence of fibre type is most outspoken, as a 5D fibre leads to a larger pull-out force due to the increased diameter and hence bonded surface, tensile strength and double hook. The influence of embedded length and inclination are less distinct. Naturally, a longer embedded length leads to a longer post-peak behaviour, provided that fibre rupture occurs at force levels larger than the maximum pull-out force.

\subsubsection{AE detection of pull-out stages}

During pull-out of a steel fibre, four regions (R1 to R4) with corresponding energy dissipation mechanisms are distinguished [16]. The AE measurements appear to be consistent with these regions. Depending on the increase of $\mathrm{AE}$ events, the energy dissipation mechanisms and stage of pull-out can be recognized. Figure 5 presents the pull-out curves and cumulative $\mathrm{AE}$ activity for six representative specimens, other specimens behave similarly.

Firstly, elastic fibre deformation and debonding along the interface in region $\mathrm{R} 1$ cause almost no AE events. Secondly, plastic deformation of the end hook occurs as the hook is straightened in R2, leading to local concrete crushing and consequently an increase of $\mathrm{AE}$ activity. In R3, the straightened fibre slides through the matrix channel, which typically leads to insignificant AE activity. However, residual fibre deformations could induce additional damage. An example of residual deformations is given in Figure 3, presenting a specimen's micro-CT scan before and halfway pullout. The fibre's end hook has been straightened, although some small curvature remains. Lastly, the frictional resistance is reduced during fibre's exit in R4. In some cases, concrete spalling at the surface results in $\mathrm{AE}$ events, depending on the amount of spalling as shown in Figure 4.

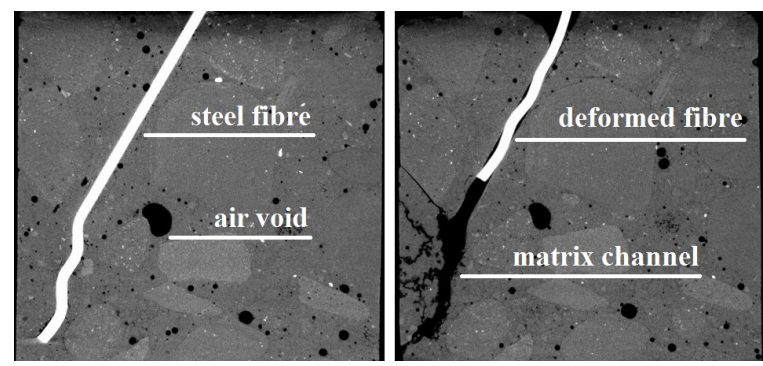

Figure 3: Micro-CT scan (left) before and (right) during pull-out of specimen 5D3-30-5.

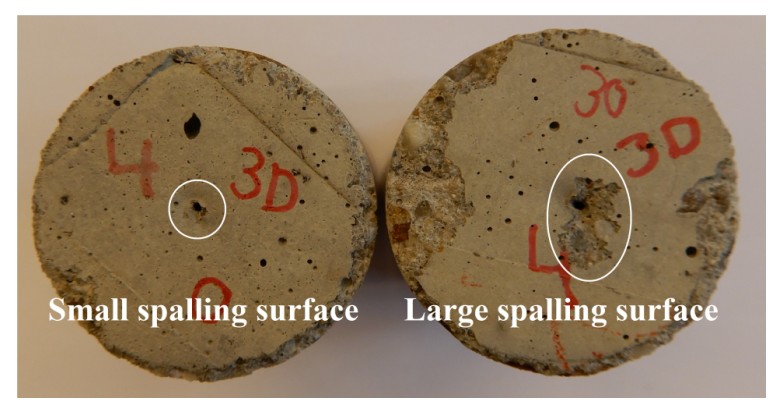

Figure 4: Example of difference in concrete spalling during fibre's exit in R4.

The use of $\mathrm{AE}$ measurements facilitates the distinction in regions of the pull-out curve. The combination of typical load-displacement curves and cumulative AE activity curves confirms the limits between each region, and the energy dissipation mechanisms due to damage are captured. Analysis of the dominant frequencies of the AE signals shows a small decrease between R1-R2 and R3. The frictional sliding movement leads to lower maximal frequencies. In some cases, $\mathrm{AE}$ activity during $\mathrm{R} 1$ has been measured. Amplitude analysis of these events reveals an amplitude range of 38 to $48 \mathrm{~dB}$, while other events during testing have a range of 63 to $73 \mathrm{~dB}$. These scattered, low-amplitude events during R1 correspond to micro-processes in the concrete matrix and are therefore not seen as part of the fibre's pull-out process.

Furthermore, the increase of AE activity in $\mathrm{R} 2$ is mainly determined by the fibre type. As expected, the double end hook of a 5D fibre leads to more energy dissipation through plastic deformation and more concrete crushing. In conclusion, the cumulative amount of AE activity is indicative for the type of fibre. 
(a)

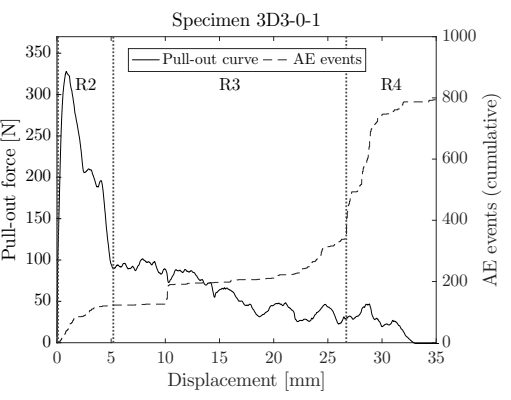

(b)

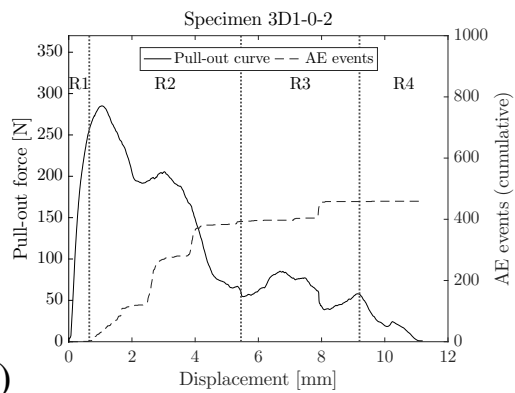

(c)

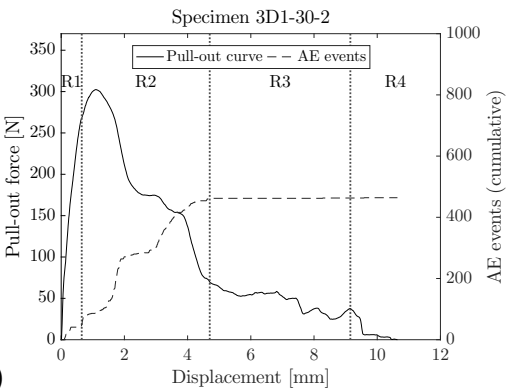

(f)

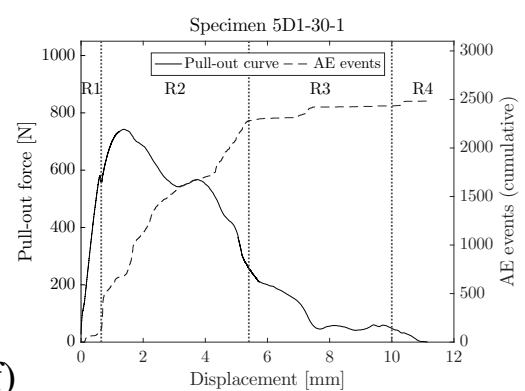

(d)

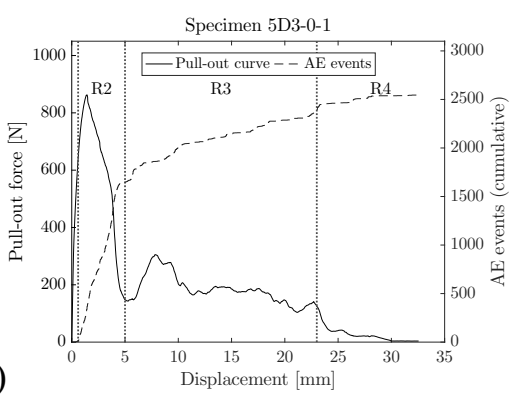

(e)

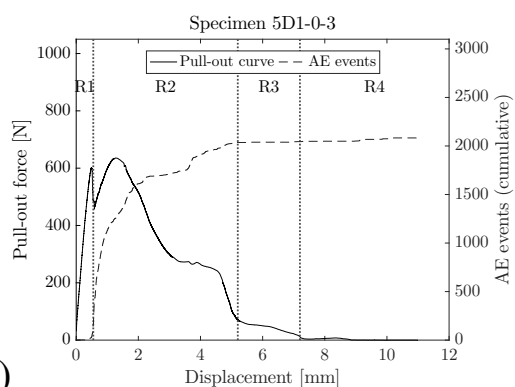

Figure 5: Monotonic pull-out curves with cumulative AE activity. Regions R1 to R4 are indicated by vertical dotted lines (except for (a) and (d), where R1 is too small compared with total displacement).

\subsubsection{Localisation of damage}

The pull-out regions as discussed before can not only be distinguished by cumulative AE activity, but also by localisation of the AE events. Figure 6 visualises the concrete specimen with initial fibre position and AE sensors. The triangles depict the localised AE sources with varying colour along test duration. It is clear that in $\mathrm{R} 2$, the increase of $\mathrm{AE}$ activity is located near the fibre's end hook were plastic deformation and concrete crushing occurs. Thereafter, AE event sources are moving upwards along the matrix channel in R3. Due to the heterogeneous nature of concrete, some events are scattered or reflected in the specimen, leading to localisations around sensors or outside the specimen.

The combination of $\mathrm{AE}$ localisation and micro-CT scanning results in a better visualisation of the damage. For specimen 5D3-305 (with an embedded length of $30 \mathrm{~mm}$ and an inclination of $30^{\circ}$, shown in Figure 7), all $\mathrm{AE}$ events are located around the fibre and the concrete damage. The increased scatter of the events is caused by reflections around the fracture plane.

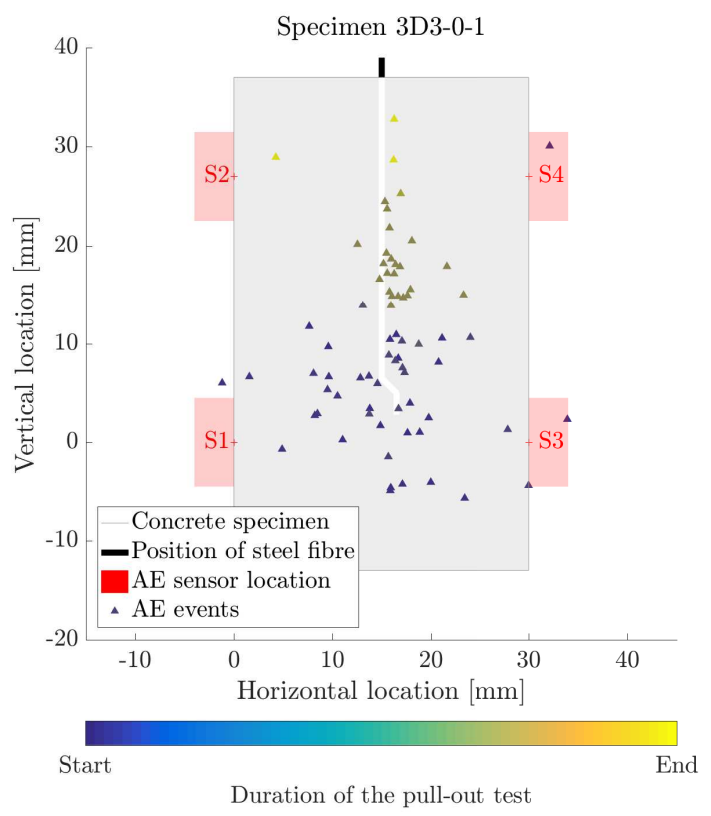

Figure 6: Localisation of $\mathrm{AE}$ events of specimen 3D3-0-1. 


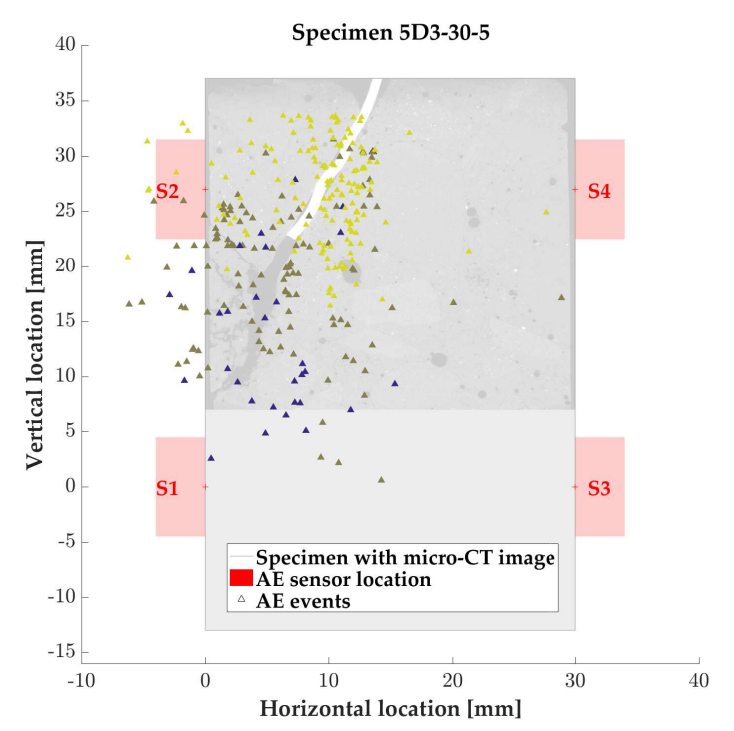

Figure 7: Localisation of AE events and microCT image of specimen 5D3-30-5.

\subsection{Monotonic behaviour of SFRC}

Four groups of SFRC elements were tested, based on the combination of fibre type (3D or 5D) and fibre content $\left(20\right.$ or $\left.40 \mathrm{~kg} / \mathrm{m}^{3}\right)$. For each group of elements, three specimens were tested monotonically. Figure 9 (a) shows the average stress-CMOD curves. As expected, the addition of fibres mostly influences the postpeak behaviour, as all flexural tensile strengths vary between 4.0 and $4.2 \mathrm{MPa}$. A higher fibre content leads to an increased post-peak strength, whereby the stronger 5D fibre leads to an enhanced behaviour compared to the 3D fibre in case of $40 \mathrm{~kg} / \mathrm{m}^{3}$. However, this expected difference is not seen in case of $20 \mathrm{~kg} / \mathrm{m}^{3}$ fibres. A possible explanation might be that most of the 5D fibres are in a bad alignment around the crack plane (i.e. the fibres are parallel with the notch and the crack plane). However, all specimens are cast in the same way and the average curve is not dominated by one possible outlier.

\subsubsection{AE activity}

The average and standard deviation of the cumulative amount of AE activity, based on localised events, are shown in Figure 8, Figure 9 (b) presents the average cumulative $\mathrm{AE}$ events during the tests. The results are in agreement with the AE measurements of individual fibre pull-out. As these measurements have shown, a 5D fibre leads to more AE activity compared to a 3D fibre. This phenomenon is attributed to the double hook that must be straightened during the pull-out process, leading to an increase of damage in the concrete matrix. The same effect causes an increase of AE activity for increasing the fibre content. Although this trend is similar to the individual fibre pull-out behaviour, it is not possible to compare the absolute values of both scales, due to the differences in experimental setup.

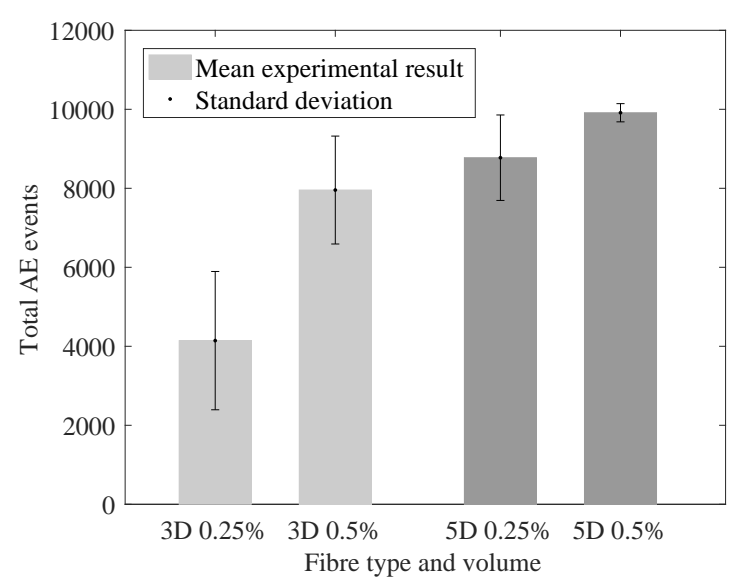

Figure 8: AE activity for each SFRC group.

All cumulative AE activity curves show a similar trend during the tests. Figure 9(c) shows the rate of AE activity (i.e. slope of the curve) expressed as percentage of its maximum value. The rate of AE activity is the highest right after reaching the peak stress around a CMOD of $0.08 \mathrm{~mm}$, immediately followed by a steep decrease of $\mathrm{AE}$ activity. It reflects the damage occurring due to concrete matrix cracking, followed by the transfer of stresses to the fibres. From the moment that fibres are being straightened (compare to $\mathrm{R} 2$ of the pull-out regions) at a CMOD of $0.15 \mathrm{~mm}$, the AE activity increases again. Thereafter, AE activity gradually decreases with growing CMOD, as more and more fibres are subjected to the frictional sliding movement (compare to R3), leading to an $\mathrm{AE}$ activity rate about $10 \%$ of the highest rate. 

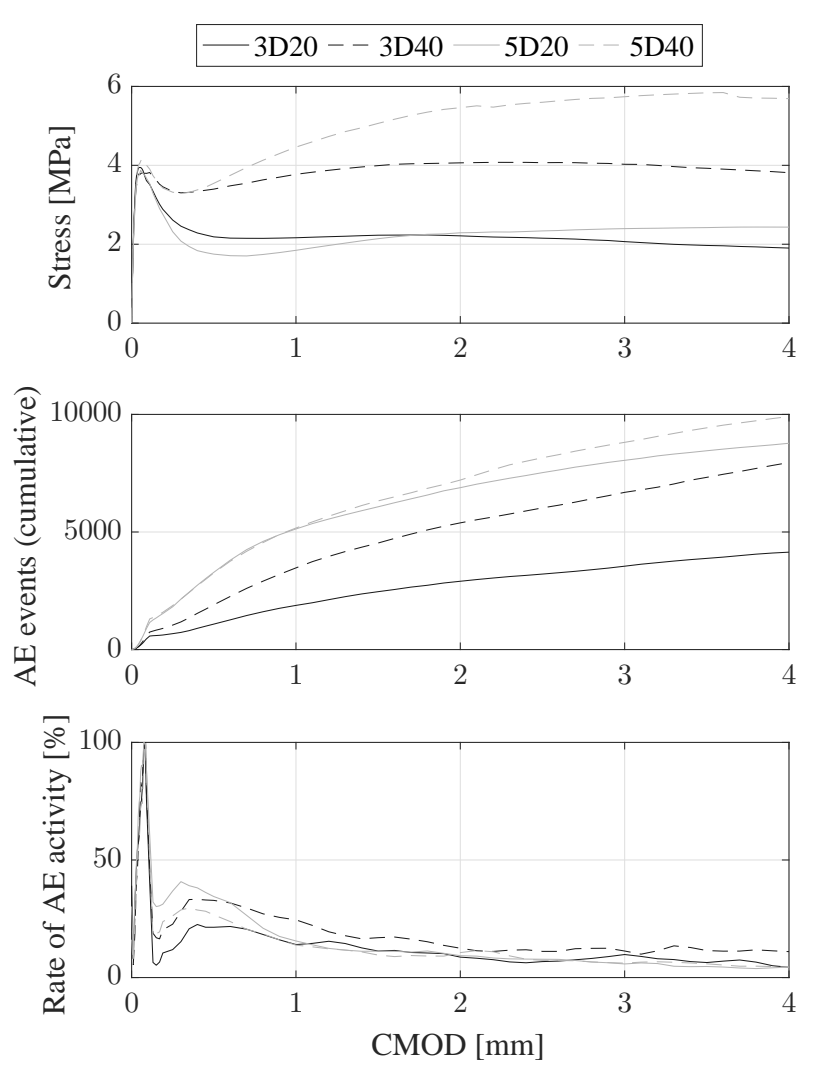

Figure 9: Average stress-CMOD curve, cumulative $\mathrm{AE}$ activity and rate of $\mathrm{AE}$ activity for each group of specimens.

Although the 3D20 and 5D20 groups showed a somewhat surprisingly similar post-peak behaviour, the AE activity is markedly different. Although most of the AE activity is caused by matrix cracking, the 5D20 group displays a high $\mathrm{AE}$ rate during the transfer of stress from matrix to fibres. The occurrence of more damage during this phase might explain the lower post-peak behaviour afterwards. For example, if most of the fibres have a high inclination with respect to their loading direction, more concrete spalling will occur when the fibres are loaded, leading to a lower individual fibre pull-out strength.

\subsubsection{Failure mode}

Besides the analysis of the AE activity, the failure mode of the events represented by the $\mathrm{AE}$ signals is of interest for this investigation.
A general method used in literature is the combined analysis of average frequency AF and RA value. The former is defined as the ratio between number of threshold crossings and signal duration (expressed in $\mathrm{kHz}$ ), the latter as the ratio between rise time and amplitude (expressed in ms/V). It is known that tensile cracks (mode I) show high AF and rather low RA, while shear damage (mode II) leads to lower AF and higher RA. More recent studies introduce the mixed mode damage, consisting of combined cracks. [17, 18]

Figure 10 presents the typical RA and AF chart for one specimen of each group, other specimens behave similarly. Although no fixed limit between the modes has been found in literature, it is clear that the majority of the damage belongs to mode I. In this research, the limit is set as a 0.1 ratio between AF and RA. Only 2 to $7 \%$ of the $\mathrm{AE}$ events is situated in the region of mixed mode. Time analysis of these events reveals that on average 31 to $57 \%$ of the mixed mode events occurs between a CMOD of 0 to $0.5 \mathrm{~mm}$. In this region, matrix cracking occurs and the stresses are transferred to the fibres. Afterwards, plastic deformation and sliding of the fibres is the main energy dissipation mechanism, which leads to less matrix damage. Localisation analysis shows a scattered pattern for the mixed mode events around the crack plane.

\subsection{Cyclic behaviour of SFRC}

\subsubsection{AE activity at multiple load cycles}

For both the individual pull-out tests and the 3PBT on SFRC elements, cyclic loading with constant load levels has been applied to investigate the material's behaviour and the AE activity under repeated loading.

Figure 11] presents two pull-out curves with cumulative AE activity, whereby the first has load cycles before peak load (1000 cycles at $0.25 \mathrm{~Hz}$ between 81 and $39 \%$ of peak load) and the second after peak load (170 cycles at $0.2 \mathrm{~Hz}$ between 80 and $52 \%$ of peak load). 


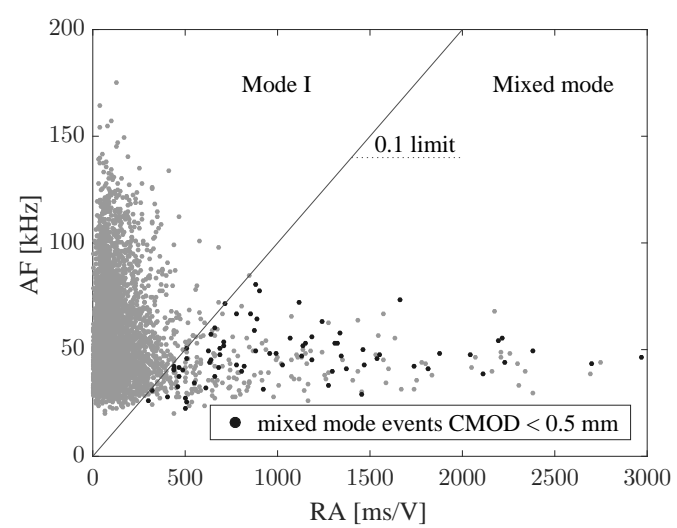

(a) specimen 3D203

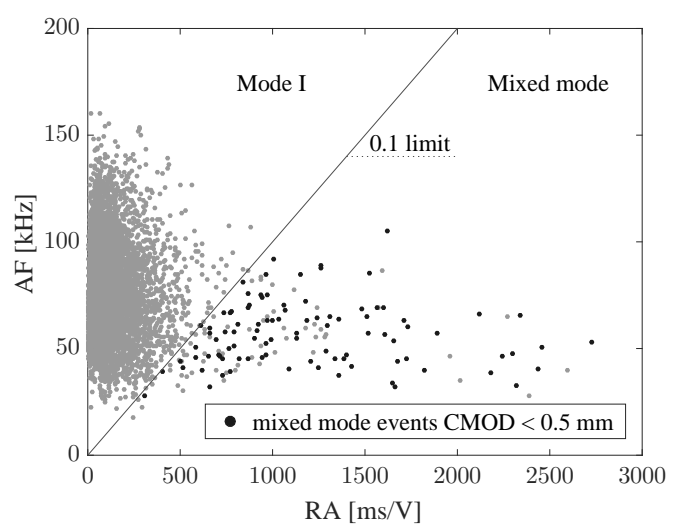

(c) specimen 5D203

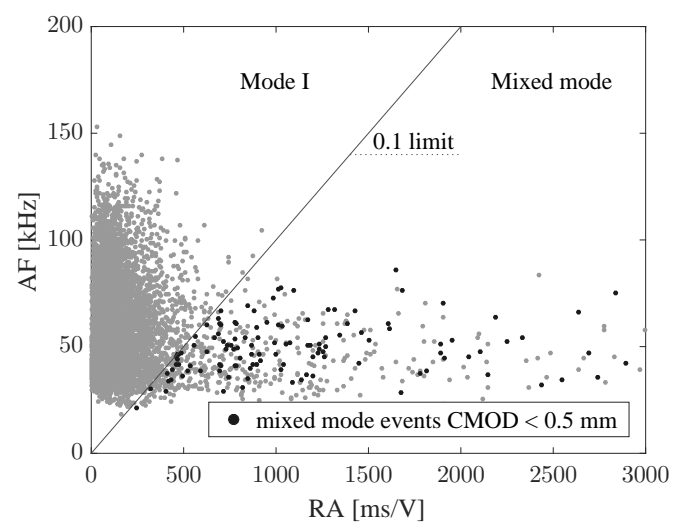

(b) specimen 3D401

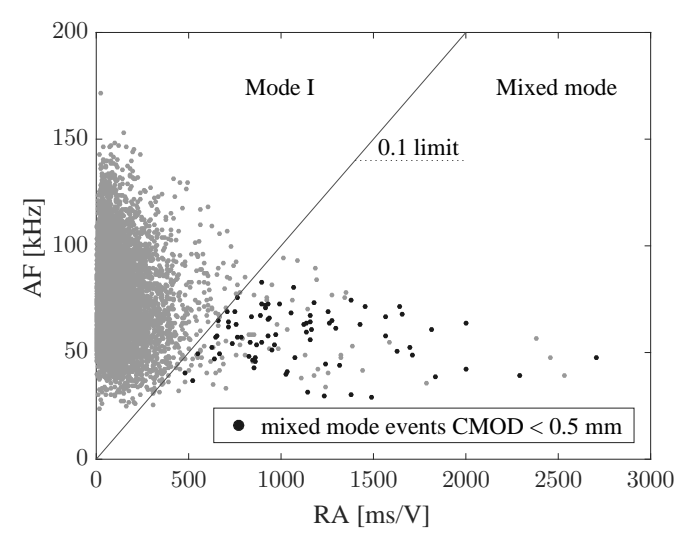

(d) specimen 5D401

Figure 10: Crack type classification based on average frequency and RA values.
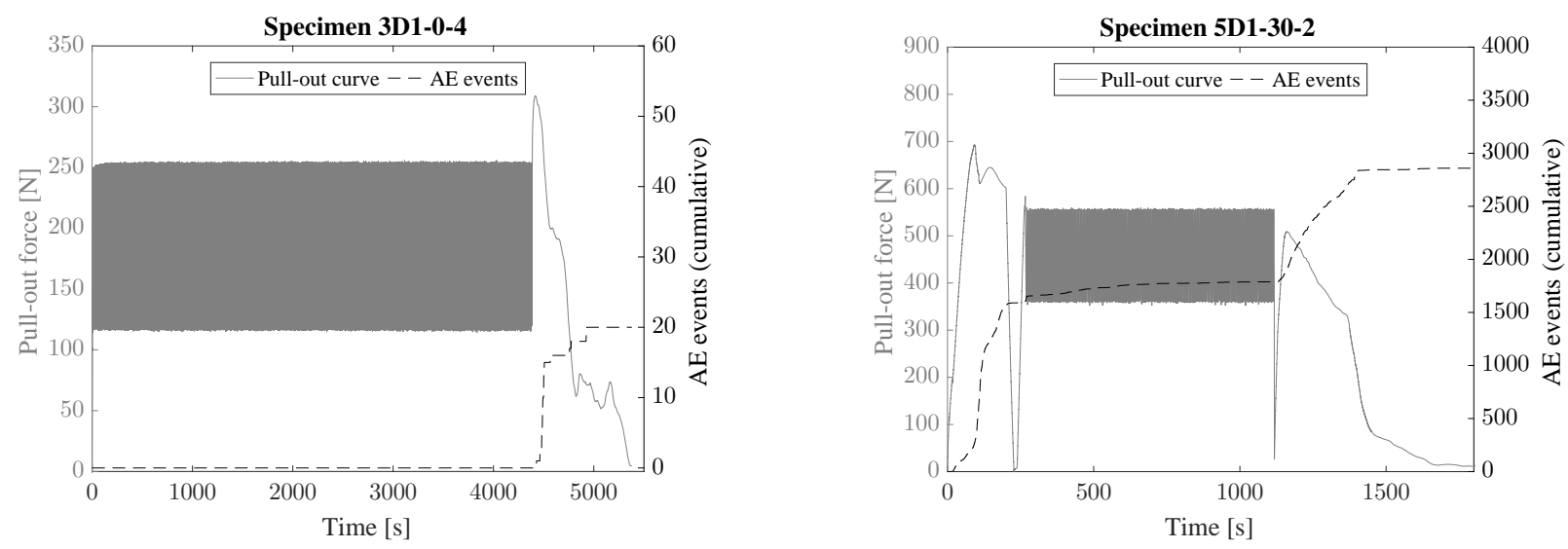

Figure 11: Pull-out and cumulative AE activity during cyclic loading before or after peak load.

Applying load cycles before peak load, i.e. during the elastic phase in $\mathrm{R} 1$, does not lead to a distinct fatigue behaviour or detectable damage, as no AE events are registered. Applying load cycles after peak load, i.e. in R2, results in a low amount of AE activity, namely $6 \%$ of the total cumulative activity. Furthermore, the displacement rate equals $90 \cdot 10^{-6} \mathrm{~mm} / \mathrm{s} \mathrm{com-}$ pared to $3 \cdot 10^{-6} \mathrm{~mm} / \mathrm{s}$ in the first case. Fatigue damage occurs due to the applied load pattern, 
but it is expected that much more load cycles or higher load limits are required to obtain fatigue failure. This conclusion is also valid for the first case, in order to obtain micro-cracking and fatigue damage.

Figure 12 shows the cyclic behaviour of an SFRC element in a 3PBT. The first figure provides the stress and cumulative $\mathrm{AE}$ activity in time, the second provides the corresponding stress-CMOD curve for the specimen. The applied cyclic loading pattern starts at a CMOD of $0.1 \mathrm{~mm}$, since the peak stress is normally reached around a CMOD of $0.08 \mathrm{~mm}$. It consists of four consecutive parts of multiple load cycles at $0.04 \mathrm{~Hz}$, namely (1) $50 \mathrm{cy}-$ cles between 90 and 44\%; (2) 70 cycles between 101 and 55\%; (3) 70 cycles between 107 and $60 \%$; and (4) 39 cycles between 115 and $68 \%$. The load limits are expressed as a percentage of the flexural tensile strength as defined by EN14651 [15] (i.e. the maximal stress at $\mathrm{CMOD} \leq 0.05 \mathrm{~mm}$ ). Since the specimen appears to withstand a larger stress afterwards, the load limits were gradually increased. The increased post-peak strength, compared to the average 3D40 curve, can be attributed to the scatter on fibre dispersion within the specimens.

During part (1) and (2), almost no AE events are detected, as the average amount equals $1 \%$ of the total cumulative activity. Moreover, the displacement rates equal $9.8 \cdot 10^{-6} \mathrm{~mm} / \mathrm{s}$. The load limits are too small to induce detectable damage, since CMOD does not exceed the previous obtained CMOD of $0.1 \mathrm{~mm}$. During part (3), CMOD exceeds the previous obtained value and consequently, an increase of $4 \%$ of $\mathrm{AE}$ events is registered, as well as a displacement rate of $31 \cdot 10^{-6} \mathrm{~mm} / \mathrm{s}$. The concrete matrix cracking continues and is followed by the transfer of stresses to the fibres. From CMOD equal to $0.15 \mathrm{~mm}$, part (4) leads to fatigue damage, since the AE events increase with $20 \%$ and the displacement increases with $209 \cdot 10^{-6} \mathrm{~mm} / \mathrm{s}$. As discussed in section 3.2.1, the fibres are being straightened from a CMOD of $0.15 \mathrm{~mm}$. Indeed, load cycles performed after this moment induce more damage than before.
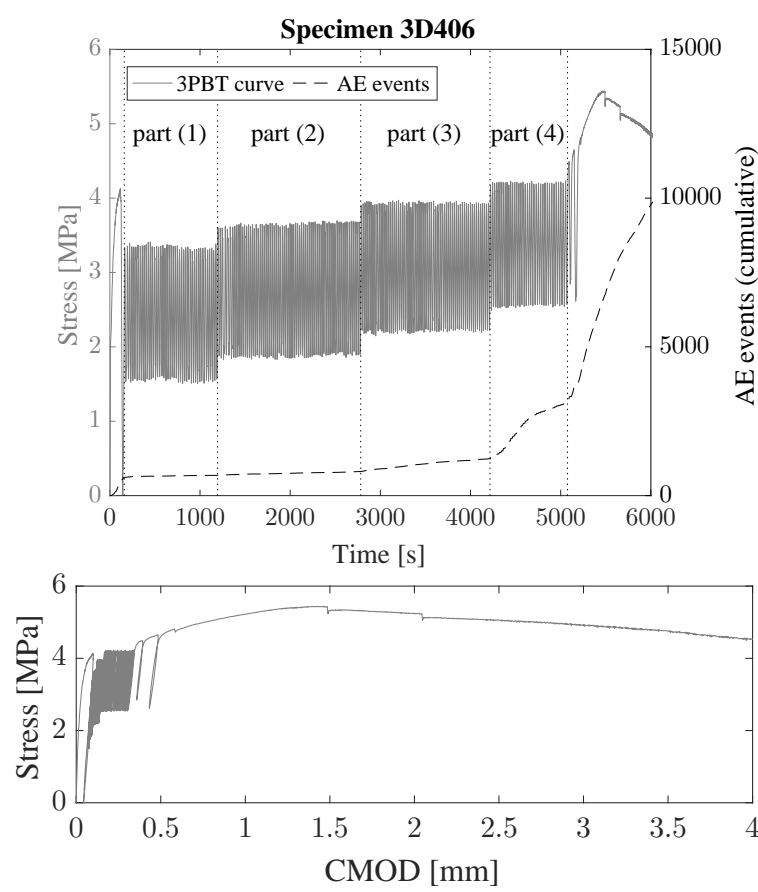

Figure 12: Stress-time curve with AE activity and stress-CMOD curve for an SFRC element.

It is clear that applying multiple load cycles does not lead to detectable fatigue damage if the cycles are applied before peak load or at too low load limits. AE activity only increases for load cycles after peak load or at high load limits. Furthermore, the amount of damage captured by AE activity can be related to the displacement rate under constant loading limits. An increasing displacement rate, and hence increasing $\mathrm{AE}$ activity, reflects the occurrence of fatigue damage, eventually leading to failure.

\subsubsection{Failure mode at multiple load cycles}

Analogous to the discussion of AE monitoring of the monotonic behaviour, it is of interest to investigate the failure mode of the events represented by the AE signals. Figure 13 presents the RA and AF chart for specimen 3D406, which is discussed in the previous section. In general, the RA and AF analysis results in similar characteristics as obtained for the corresponding monotonic behaviour. $4.6 \%$ of the $\mathrm{AE}$ events belongs to the mixed mode region and $32 \%$ of these events occurs between a CMOD of 0 to $0.5 \mathrm{~mm}$. 
However, time analysis is performed in Figure 14. Both the stress-time curve and the AE events during the test are plotted, with indication of the different loading parts. The AE events are presented by their AF to RA ratio, in order to distinguish mode I and mixed mode events. The limit is set to 0.1 , as discussed in section 3.2.2. It shows that during part (1), (2) and (3) of the applied load pattern, no mixed mode events occur. For low displacement rates, the occurring damage only exists of mode I damage, i.e. tensile cracks. Mixed mode damage only occurs at higher displacement rates, when more damage is induced.

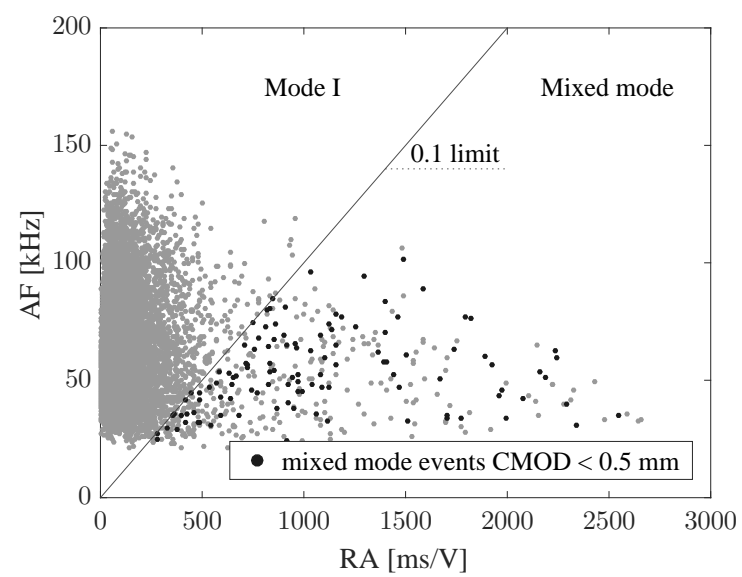

Figure 13: Crack type classification for specimen 3D406.

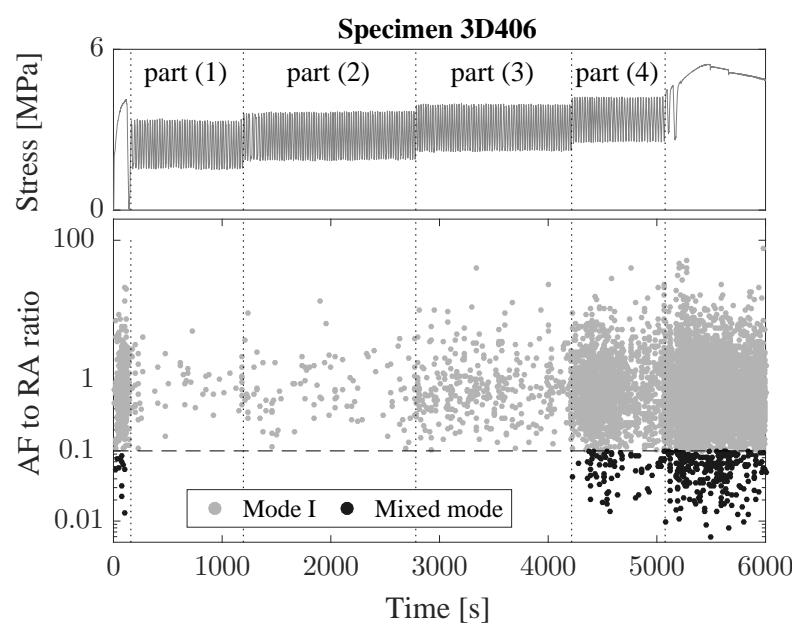

Figure 14: Time analysis of applied loading pattern and crack type classification.

\section{CONCLUSIONS}

This paper discusses an AE-based analysis of damage mechanisms in SFRC under monotonic and cyclic loading, by performing individual fibre pull-out and SFRC bending tests. AE monitoring and micro-CT scanning lead to indepth insight in the material's behaviour.

Firstly, four different pull-out stages can be distinguished by the cumulative AE activity. Each energy dissipation mechanism leads to certain damage, resulting in $\mathrm{AE}$ events. Combination of micro-CT scans and AE localisation results in a damage visualisation that agrees with the different stages. Furthermore, the amount of AE activity can be related to the fibre's type.

Secondly, the total AE activity of SFRC bending tests indicates the fibre type and volume as well, although it is not possible to conclude a one-to-one relationship. By analysis of the AE activity rate, matrix cracking, transfer of stresses to fibres and fibre pull-out are distinguished, whereby the individual fibre pull-out processes are recognized. Furthermore, analysis of average frequency and RA-value shows the failure mode of the occurring damage. 98 to $93 \%$ of the damage belongs to mode I, i.e. tensile cracks, and 2 to $7 \%$ to mixed mode damage. The largest increase of mixed mode damage occurs for a CMOD between 0 and $0.5 \mathrm{~mm}$.

Thirdly, the cyclic behaviour of both fibre pull-out and bending tests is investigated. Applying multiple load cycles only leads to detectable fatigue damage if applied after the peak load or at sufficiently high load limits. Load cycles not meeting these requirements lead to similar behaviour as monotonic loading. An increase of displacement rate (under constant loading limits) is related to an increase of $\mathrm{AE}$ activity and the occurrence of mixed mode instead of only mode I damage.

\section{AKNOWLEDGEMENTS}

The authors gratefully acknowledge the financial support of Research Foundation Flanders (FWO, grant no. 1S32717N) and the supply of steel fibres of Bekaert nv. 


\section{REFERENCES}

[1] Parvez, A., and Foster, S.J. 2015. Fatigue behaviour of steel-fiber-reinforced concrete beams. Journal of Structural Engineering 141(4).

[2] Germano, F., Tiberti, T., and Plizzari, G. 2016. Post-peak fatigue performance of steel fiber reinforced concrete under flexure. Materials and Structures 49(10):4229-4245.

[3] Landis, E.N., and Keane, D.T. 2010. Xray microtomography. Materials Characterization 61:1305-1316.

[4] Wevers, M., et al. 2012. X-ray computed tomography for non-destructive testing. In Proceedings of International Conference on Industrial Computed Tomography 2012; Wels, Austria; pp. 1-10.

[5] Verstrynge, E., et al. 2016. Experimental study of failure mechanisms in brittle construction materials by means of X-ray microfocus computed tomography. In Proceedings of the Ninth International Conference on Fracture Mechanics of Concrete and Concrete Structures; Berkeley, California, USA; pp. 1-10.

[6] Landis, E.N., Kravchuk, R., and Loshkov, D. 2019. Experimental investigations of internal energy dissipation during fracture of fiber-reinforced ultra-high-performance concrete. Frontiers of Structural and Civil Engineering 13(1): 190-200.

[7] Noorsuhada, M.N. 2016. An overview on fatigue damage assessment of reinforced concrete structures with the aid of acoustic emission technique. Construction and Building Materials 112:424-439.

[8] Wevers, M. 1997. Listening to the sound of materials: acoustic emission for the analysis of material behaviour. NDT\&E International 30(2):99-106.

[9] Grosse, C.U., and Ohtsu, M. 2008. Acoustic Emission Testing. Springer 978-3-54069895-1.
[10] Aggelis, D.G., Soulioti, D.V., Sapouridis, N., Barkoula, N.M., Paipetis, A.S., and Matikas, T.E. 2011. Acoustic emission characterization of the fracture process in fibre reinforced concrete. Construction and Building Materials 23:3532-3536.

[11] Shahidan, S., Pulin, R., Bunnori, N.M., and Holford, K. 2013. Damage classification in reinforced concrete beam by acoustic emission signal analysis. Construction and Building Materials 45:78-86.

[12] Kravchuk, R., and Landis, E.N. 2018. Acoustic emission-based classification of energy dissipation mechanisms during fracture of fiber-reinforced ultra-highperformance concrete. Construction and Building Materials 176:531-538.

[13] CEN. 2009. NBN EN 12390-3: Testing hardened concrete - Part 3: Compressive strength of test specimens. European Committee for Standardization.

[14] Fédération Internationale du Béton (fib). 2013. fib Model Code for Concrete Structures 2010. Wilhelm Ernst und Sohn Verlag für Architektur, Berlin (Germany).

[15] CEN. 2014. EN 14651: Test method for metallic fiber concrete - measuring the flexural tensile strength (limit op proportionality (LOP), residual). European Committee for Standardization.

[16] Pompo, A., Stupak, P., Nicolais, L., and Marchese, B. 1996. Analysis of steel fibre pull-out from a cement matrix using video photography. Cement and Concrete Composites 18:3-8.

[17] Behnia, A., Chai, H.K., and Shiotani, T. 2014. Advanced structural health monitoring of concrete structures with the aid of acoustic emission. Construction and Building Materials 65:282-302.

[18] Soulioti, D., Barkoula, N.M., Paipetis, A., Matikas, T.E., Shiotani, T., and Aggelis, D.G. 2009. Acoustic emission behavior of steel fibre reinforced concrete under bending. Construction and Building Materials 23:3532-3536. 